\title{
Teachers' knowledge for teaching compound interest
}

\author{
Author: \\ Craig Pournara ${ }^{1}$ \\ Affiliation: \\ ${ }^{1}$ Wits School of Education, \\ University of Witwatersrand, \\ South Africa \\ Correspondence to: \\ Craig Pournara \\ Email: \\ craig.pournara@wits.ac.za \\ Postal address: \\ Box 1531, Pinegowrie 2013, \\ South Africa \\ Dates: \\ Received: 02 Aug. 2013 \\ Accepted: 07 Nov. 2013 \\ Published: 29 Nov. 2013 \\ How to cite this article: \\ Pournara, C. (2013). \\ Teachers' knowledge for \\ teaching compound interest. \\ Pythagoras, 34(2), Art. \#238, \\ 10 pages. http://dx.doi. \\ org/10.4102/pythagoras. \\ v34i2.238

\section{Copyright:} \\ (C) 2013. The Authors. \\ Licensee: AOSIS \\ OpenJournals. This work \\ is licensed under the \\ Creative Commons \\ Attribution License.
}

Read online:
There is increasing acknowledgement that teachers' knowledge for teaching mathematics is multifaceted and topic specific. Given the paucity of research on the teaching and learning of financial mathematics in general, little can be known about teachers' knowledge for teaching compound interest. However, since financial mathematics is a component of the school curriculum in South Africa, and an important element of financial literacy more broadly, attention needs to be given to knowledge for teaching financial mathematics, and compound interest in particular. Drawing from a larger study in which the author taught a financial mathematics course to pre-service secondary mathematics teachers, a theoretical elaboration is provided of the underlying mathematics of compound interest, and connections with the world of banking. Based on findings from the study, two key student errors are identified: the over-generalisation of linear thinking in multiplicative scenarios, and the over-generalisation of reversible operations in percentage-change scenarios. Taken together, teachers' knowledge of relevant mathematics, of the banking context and of learners' conceptions will contribute to building a knowledge-base for teachers' knowledge for teaching compound interest.

\section{Introduction}

The issue of teachers' mathematical knowledge for teaching has been on the agenda in mathematics education research since Shulman's seminal work in the eighties (Shulman, 1986, 1987). There is now agreement that teachers' knowledge is both multifaceted and topic specific (Adler \& Ball, 2009). In areas of secondary mathematics that have been widely researched, such as introductory algebra, functions and calculus, there is a body of knowledge that elaborates the mathematical concepts at school level, that provides insights into learners' conceptions in relation to the topics, and that proposes a range of topic-specific pedagogical approaches to support learning of the topic (e.g. Even, 1990, 1993; Thompson, 1994; Thompson \& Thompson, 1996; Zandieh, 2000). However, there are many concepts and topics in the school curriculum that have received little attention. Financial mathematics is one of these. We know very little, for example, about learners' conceptions of compound interest or about the most effective ways of teaching compound interest, and what we might claim to 'know' is largely anecdotal.

Therefore, before considering what knowledge teachers need for teaching compound interest, it is necessary to consider more deeply the notion of compound interest in the context of school mathematics. In this article I provide a theoretical elaboration of compound interest against which to explore learners' conceptions, teachers' knowledge and appropriate pedagogies. I focus on mathematical and financial aspects of compound interest that are pertinent to teaching at secondary school level.

This article is drawn from a larger study of pre-service secondary mathematics teachers learning financial mathematics in a course specifically designed for teachers (Pournara, 2013). The data drawn on in this article come from video records of contact sessions during the course and during small group tutorial sessions, as well as students' written work from tutorials, journals and course assessments.

Whilst Shulman proposed the distinction between subject matter knowledge (SMK) and pedagogical content knowledge (Shulman, 1986, 1987), this distinction is not so easy to operationalise (Ball, Thames \& Phelps, 2008). And so following others in the field (e.g. Adler, 2005; Adler \& Davis, 2006; Huillet, 2009) I refer to mathematics for teaching as an amalgam of subject matter knowledge and pedagogical content knowledge, which consists of aspects of knowledge that are mainly mathematical and others that are mainly pedagogical. In addition, given my focus on financial mathematics, I add knowledge of financial aspects.

In order to provide a backdrop for the article, I begin by locating compound interest in the South African school mathematics curriculum and use examples from local textbooks to illustrate typical 
tasks. I also briefly summarise the small body of research findings on learning of compound interest. Thereafter I focus in turn on mathematical, financial and pedagogical aspects of teachers' knowledge in relation to compound interest.

\section{Compound interest in the South African school curriculum}

The notion of interest on money is introduced in the South African Mathematics ${ }^{1}$ curriculum in Grade 7 (Department of Education, 2002), starting with simple interest, followed in later grades by compound interest with annual compounding, and then multiple compounding periods per year. In Grade 11 the notions of nominal and effective interest rates are introduced, together with problems involving changes in interest rates and depreciation. Here are three typical examples of textbook questions on compound interest:

Question 1: Brett has R7500, which he wants to invest for 5 years. Which savings plan will yield more interest: simple interest at $14 \%$ p.a. or compound interest at $12 \%$ p.a.? (Cross et al., 2005, p. 60)

Question 2: A sum of money was invested at a nominal annual interest rate of $4.25 \%$ per annum compounded quarterly. After five years this investment was worth R4500.

- What sum of money was invested?

- Give the effective annual interest rate for this example. (Bennie, Blake \& Fitton, 2006, p. 140)

Question 3: R28 000 is invested for 10 years. The interest is calculated at $9.3 \%$ p.a. compounded monthly for the first four years. After four years the interest rate is increased to $11.8 \%$ p.a. compounded quarterly. Calculate the value of the investment at the end of 10 years. (Laridon et al., 2006, p. 38)

Question 1 is typical in both local and international texts, and requires students ${ }^{2}$ to distinguish between calculating simple and compound interest. Students will either do the necessary iterative calculations for five years, or they will use the simple and compound interest formulae. It is assumed here that compounding is annual since it is not stated otherwise. By contrast, in the world of banking, compounding is assumed to be monthly unless specified otherwise. Question 2 is a typical Grade 11 question dealing with quarterly compounding, and with nominal and effective interest rates. It requires students to identify the rate per period and the associated number of compounding periods. Question 3 deals with a change in interest rates and in compounding periods. A key aspect here is the different rate per period for two time segments of the question. This question is typical of textbook questions that make use of timelines.

From the perspective of the banking world, all three questions reflect very simplified scenarios. For example, it is assumed

1.In this article I focus only on the secondary Mathematics curriculum although financia mathematics is also a component of the Mathematical Literacy curriculum.

$2 . I$ refer to both students and learners in this article. In some instances the distinction is obvious, as in references to research with university students. In other cases the ambiguity is deliberate because I make the assumption that errors made by pre-service teachers are also likely to be made by learners in schools. that deposits remain in the bank for full periods and, by implication that they are made at the beginning of the period. No attention is given to the number of days in the year or the number of days in a month. In question 3 the big increase in interest rate and the shift from monthly to quarterly compounding are not likely in the banking world.

It is important to note the curriculum constraints with regard to financial mathematics. Financial mathematics is allocated two weeks of teaching time, and $5 \%$ of the total marks in final assessments in Grades 10-12 (Department of Basic Education, 2011). Given these curriculum constraints, one needs to be realistic about how deeply teachers can deal with compound interest. One also needs to consider the typical questions that learners will encounter in their text books, and in assessments. All this constrains what it is possible to teach and learn in schools. This, in turn, frames the nature and extent of the teachers' knowledge for teaching financial mathematics in schools. Whilst acknowledging the curriculum constraints, in this article I elaborate a range and depth of knowledge of compound interest that might enable teachers to teach the content with mathematical insight and increased awareness of the realities of the banking world. I do not propose that depth and breadth of knowledge is a requirement to teach compound interest well, but rather that it is a level to which teachers may aspire.

\section{Research on conceptions of compound interest}

Whilst there is very little research on financial mathematics in general, the following findings can be gleaned from the limited research on students' knowledge of compound interest and their ability to work with it. Whilst it is difficult to determine the extent to which the findings may be generalisable beyond the original studies, the findings all resonate with my experiences of students' learning of compound interest:

- University students as well as the broader population have difficulty in executing compound interest calculations (Dempsey, 2003; Organisation for Economic Cooperation and Development, 2005).

- University students cannot easily distinguish the impact of simple interest from that of compound interest on the growth of a principal amount (Beal \& Delpachitra, 2003).

- University students, including 'business majors', lack knowledge of the impact of increasing the frequency of compounding (Chen \& Volpe, 1998).

- University students have difficulty in identifying which formula or procedure to use for time value calculations involving single amounts or multiple payments (Jalbert, Jalbert \& Chan, 2004).

- High school learners may not convert the nominal annual rate to an appropriate rate per period, and may not easily distinguish whether a formula calculates the accumulated interest or the cumulative balance (Geiger \& Goos, 1996).

The workplace-based research by Hoyles and Noss and others (e.g. Hoyles, Noss, Kent \& Bakker, 2010; Noss \& Hoyles, 1996a, 1996b) provides the greatest insight into the learning of 
compound interest. They found that percentage, compound growth and graphs were pervasive in daily financial work, and that employees' grasp of percentage and interest was deeply intertwined with their working contexts. However, they were not aware of the underpinning mathematics, such as the multiplicative structures connecting percentages and interest rates. Hoyles et al. (2010) also emphasised the importance of being able to communicate with the customer to explain printouts, to answer queries, and to provide meaningful explanations about the benefits of one product over another. There are similarities between the demands of this work and teaching since both require an ability to distil the essence of the issue and to communicate this to another who is less knowledgeable.

One of the key insights from Bakker, Kent, Noss, Hoyles and Bhinder (2006) relates to interest and percentage increase or decrease, and is therefore relevant to school mathematics. Based on interventions with employees, they argue that an approach of multiplying factors is preferable to adding or subtracting percentages. For example, in the case of adding interest of $6 \%$ p.a. or calculating a discount of $25 \%$ on some amount, $P$, they suggest that learners (or students or employees) should be encouraged to work with the multiplicative forms of $P(1+0.06)$ and $0.75 \times P$ rather than $P+\frac{6}{100} P$ or $P-P \times \frac{25}{100}$. The multiplicative form has several advantages, including its efficiency and its similarity to the compound interest formula.

\section{Mathematical aspects of teachers' knowledge}

In this section I distinguish the key features of interest in general and of compound interest in particular. I discuss links between compound interest and related mathematical concepts, and I show that two different derivations of the compound interest formula require different conceptions by learners. Whilst mathematics is always in the foreground in this section, teaching issues are continually present, albeit in the background.
I draw on Ma's (1999) notions of depth and breadth with regard to teacher's mathematical knowledge. For her, depth of understanding concerns the ability to connect a concept or a topic 'with more conceptually powerful ideas of the subject' (p. 121) so that the power of a mathematical idea is related to its proximity to the structure of the discipline. A mathematical idea that is closer to the structure of the discipline underpins more topics and hence has more 'mathematical influence' (my term) and thus mathematical power. By contrast, breadth of understanding is related to the ability to connect a concept or topic with concepts or topics of similar or less conceptual power. Inspired by Ma's work and drawing loosely on her idea of knowledge packages for primary mathematics, I propose the hierarchies shown in Figure 1 and Figure 2. Concepts that are higher in the diagram build on those that are lower down. I use italics when referring to the nodes (text boxes) in the diagrams.

In network diagrams such as these it is often possible to argue that all components are linked in some way to each other, and thus to insert links between all nodes in the diagram. This is seldom productive because it obscures the key relationships in the mass of connecting lines. I have therefore chosen to represent only the key links between components.

\section{A hierarchy of interest concepts}

In Figure 1 I present a hierarchical network of links between key mathematical concepts in simple and compound growth. The central (purple) cluster indicates mathematical concepts, with percentage at the lowest level, and extends to progressions. Following Ma (1999), this arrangement reflects that, for example, linear growth is a mathematically more powerful concept than geometric progressions because it underpins a larger number of mathematical topics (although other topics that it underpins, such as rates of change, are not indicated here). The right (green) cluster and left (light blue) clusters indicate concepts dealing with increasing and decreasing growth respectively.

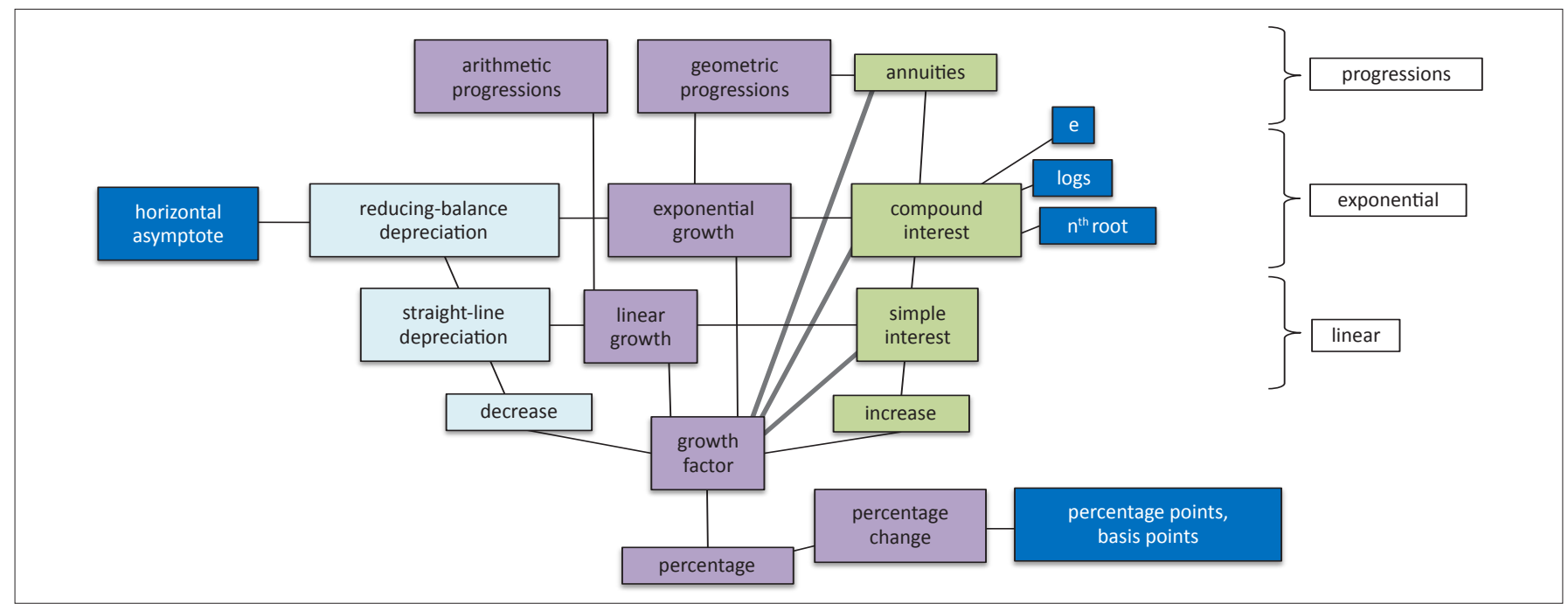

FIGURE 1: A hierarchy of interest concepts. 
At the lowest level of the diagram, links are shown between percentage, percentage change and their application in financial contexts in the form of percentage points and basis points.

Building on percentage, and based on the recommendations of Bakker et al. (2006), is the concept of growth factor. I use this term for the factor that is multiplied by the 'starting value', which could be the principal amount, original price, and so on. In the case of simple increase or decrease it is $(1 \pm i \cdot n)$ and in the case of compound increase or decrease it is $(1 \pm i)^{n}$. I shall use the term unit growth factor for $(1 \pm i)$ in both simple and compound increase and decrease. This term is not indicated in the diagram.

Moving vertically, the diagram contains three horizontal clusters: linear growth, exponential growth and progressions, all of which build on growth factor. I place linear growth below exponential growth since constant additive change is a simpler concept than constant multiplicative change (Brown, Küchemann \& Hodgen, 2010). At the top level, progressions builds on the relevant growth from the levels below. Moving horizontally within each cluster, linear growth is applied in the contexts of simple interest and straight line depreciation whilst exponential growth is applied in compound interest and reducing balance depreciation. Geometric progressions are applied in annuities.

The bold lines connecting growth factor to simple interest, compound interest and annuities indicate the importance of the notion of growth factor in calculations involving each of these concepts. The outer (dark blue) boxes on either side of the diagram indicate connections between the aspects of financial mathematics and other key mathematical concepts such as $n^{\text {th }}$ roots, logs and horizontal asymptotes. This reflects Ma's (1999) notion of breadth. These mathematical concepts are necessary when dealing with various aspects of compound increase and decrease at school level. For example, logs are required when determining the length (or number of compounding periods) of an investment. The connection with $e$ applies to continuous compounding.

\section{A network of concepts relating to growth factor}

In Figure 2, I expand the growth factor component of Figure 1 by focusing on the processes and concepts involved in calculating interest with particular reference to the school curriculum. I therefore refer to interest at the base of the network. I distinguish three main components: the calculation method, the interest rate and the compounding frequency. Each of these has several interrelated sub-components. Different colours (or shades of grey) have been used to distinguish the three main components, their sub-components and the links. As in Figure 1, I have represented only the key links between components.

I begin with the calculation method: interest calculated on the principal amount is simple interest, whereas interest calculated on the latest balance is compound interest. Daily interest calculations, as done in banks, are simple interest calculations that produce the balance on which interest is compounded at the end of the month, hence the links to simple interest and compound interest.

With regard to interest rate, the key distinction is between nominal rates and effective rates. In addition, the rate per period is an essential component and might even be considered the central idea in the entire network since it connects interest rate, compounding frequency and calculation method. I include the interest rate of an annuity for completeness since it is not required in the school curriculum (because it requires numerical methods). Consequently I have not inserted links to other sub-components such as rate per period and compound interest since this would complicate the diagram.

The compounding frequency determines the amount of interest that will accumulate. I distinguish annual compounding from multiple compoundings per year, and continuous compounding. Once again this is for completeness since continuous compounding is not part of the school curriculum.

Nominal interest rate is connected to effective interest rate (by means of a broken line) since the two notions are dependent on each other. Nominal rate is linked to annual compounding, rate per period and simple interest because it is the rate used in the respective procedures. It is also linked to rate per period since it is one of the inputs that determine the rate per period.

Rate per period also has links from compound interest and multiple compoundings per year. The nominal rate, together with number of compounding periods, determines the interest rate for the smaller periods. The link from compound interest indicates the need to determine a rate per period when there are multiple compoundings per year. There is also has a link to effective interest rate since the rate per period is used in calculating the effective rate.

Effective interest rate has links from compound interest, multiple compounding periods, nominal rate and rate per period. These sub-components work together to produce 'interest on interest' and the effective rate is the annual interest rate, compounded once, that generates the same yield as interest on interest. Effective rate also has a link from annual compounding and simple interest. The annual compounding

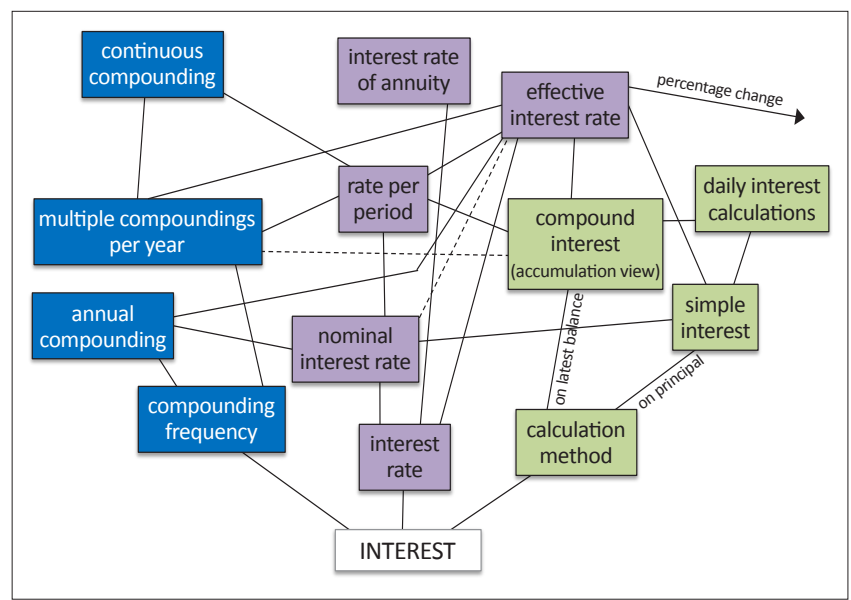

FIGURE 2: A network of concepts relating to growth factor. 
link exists because the most important effective rate is the annual effective rate which assumes annual compounding. The simple interest link is important because it supports an explanation of the effective rate in the following manner: if accumulated interest is removed from the account after each interest period, the balance returns to the principal amount. This becomes a simple interest situation because interest is calculated on the principal amount each time. By contrast, if the interest remains in the account, then applying the same rate per period and appropriate compounding frequency will produce a higher yield. This yield, expressed as a percentage of the principal, is the effective annual rate. Since effective rate can be seen as percentage increase, the link to percentage change in Figure 1 has been included.

Continuous compounding has links from compound interest and rate per period. It assumes the number of compoundings per year tends to infinity, thus reaching the limiting situation which can be shown to equal $P e^{i t}$ where $P=$ principal, $i=$ nominal annual rate, and $t=$ time in years.

It is possible to make a link between rate per period and simple interest. This would be relevant if simple interest is determined more frequently than annually. A hypothetical example is a notice deposit where interest is paid out quarterly and thus a quarterly rate would be used to determine the accumulated interest per quarter.

Based on my teaching of financial mathematics to pre-service teachers, and conversations with teachers in schools, it appears that the notion of rate per period may be a key element of learning compound interest. It brings together compound interest, multiple compounding periods and nominal rate. This requires further research.

\section{Deriving a formula for compound interest}

The compound interest formula is deceptively elegant and its subtleties take time to grasp. In this section I discuss two derivations of the formula from both a mathematical and a pedagogical perspective, and show what it might take to appreciate the formula as an algebraic representation of exponential growth.

The first derivation uses an additive approach and requires an operational view (Sfard, 1991). It builds directly on the process of adding interest to the principal amount. In Figure 3, I illustrate the steps in this process.

\begin{tabular}{|ccll|}
\hline Line & $\begin{array}{c}\text { End of } \\
\text { period }\end{array}$ & Expression for process of compounding & $\begin{array}{c}\text { Simplified } \\
\text { expression }\end{array}$ \\
\hline 1 & 1 & $A_{1}=P+P i$ & $A_{1}=P(1+i)$ \\
2 & 2 & $A_{2}=P(1+i)+P(1+i) i=P(1+i)[1+i]$ & $A_{2}=P(1+i)^{2}$ \\
3 & 3 & $A_{3}=P(1+i)^{2}+P(1+i)^{2} i=P(1+i)^{2}[1+i]$ & $A_{3}=P(1+i)^{3}$ \\
4 & $\vdots$ & & \\
5 & $n$ & $A_{n}=P(1+i)^{n-1}+P(1+i)^{n-1} i=P(1+i)^{n-1}[1+i]$ & $A_{n}=P(1+i)^{n}$ \\
\hline
\end{tabular}

$A_{n}=$ amount accumulated at the end of period $n, P=$ principal amount invested, $i=$ interest rate per period.

FIGURE 3: An additive approach to deriving the compound interest formula.
In line 1 the principal amount gains interest for one period, so the accumulated amount is the sum of $P$ and the interest on $P$. This is then factorised to simplify the algebraic expression. The new expression, $P(1+i)$, needs to be seen as a single entity rather than the product of a quantity and scalar multiple - it is the closing balance at the end of period 1 . The same process repeats at the end of each compounding period, but in choosing to work each time with the principal, $P$, rather than an iterative formula (that would substitute $A_{n}$ ), the algebraic representation starts to get clumsy. For example, in line 2, the student must recognise that $P(1+i)$ is the new amount on which interest will be gained, and be able to separate $P(1+i)$ from the adjacent $i$ in order to recognise the similarity with the structure in line 1 . As the process continues, it leads to the general formula for the accumulated amount at the end of period $n, P(1+i)^{n}$. In this context, it is obvious that $n$ represents the number of times that interest is compounded.

The intermediate steps shown in the 'process' column enable one to distinguish between the opening balance for each period and the amount of interest that accumulates in that period.

From the point of view of algebraic manipulation, it is fortunate that the expression simplifies elegantly each time, reducing to an exponential form. In the 'process' column I have deliberately used square brackets to distinguish between the accumulated amount at the beginning of the period and the new factor of $[1+i]$ that emerges from factorisation. This step of factorising is key in establishing the formula. If one chooses to expand rather than factorise, one ends up with a very messy expression such as $A_{3}=P i^{3}+3 P i^{2}+3 P i+P$ at the end of period 3 . This expression does not point obviously towards the elegant formula.

Whilst those who have done more advanced mathematics may recognise in this expression the binomial expansion of $(1+i)^{3}$, those who are deriving the formula at school level will not have encountered this expansion and so their manipulation takes them away from the desired formula rather than closer to it. This may not be obvious to them - they have expanded and then collected like terms, so they may initially feel that they are making progress. However, in my experience, they soon realise that this formula gets increasingly complex and, although there may be a recognisable pattern and a repeatable process, the output for each period cannot be succinctly reduced to a 'simple' formula.

Students may not easily recognise the multiplicative structure in the process until they are able to produce the simplified expression. They may then accept that the growth is exponential only because of the form of the expression, not because of the process that has led to the formula. This makes it even more important that they understand the derivation of the formula - to recognise that adding to the whole a scalar multiple of the whole produces an exponential relationship.

However, a disadvantage of the algebraic compression in the last column is that it may obscure the interest-gaining process 
until one recognises that multiplying repeatedly by a factor of $(1+i)$ models the process of growing by a proportion of the original quantity, which, in financial terms, is the gaining of interest on interest. This is not a simple transition. It requires that students operate with the object $(1+i)$. Drawing on Sfard's (1991, 1992; Sfard \& Linchevski, 1994) operationalstructural distinction, initially students may see $P(1+i)$ only as the outcome of the process of algebraic simplification and not as an object to be operated with. Once students accept $P(1+i)^{k}$ and $(1+i)$ both as objects, they may be satisfied to work as in Figure 4.

In Figure 4, the student must recognise that for any month $k$, the expression $P(1+i)^{k-1}$ represents the accumulated amount from the previous month, and that the compounding process can be modelled by multiplying by a factor of $(1+i)$. There is no explicit separation of the accumulated amount from the interest. Each factor of $(1+i)$ should be seen as a unit growth factor over a particular time period, but it is not possible to determine the interest accumulated for any time period without further (albeit simple) calculations. As Bakker et al. (2006) argue, becoming familiar with this multiplicative approach is an essential step in working with percentage. Once students accept the exponential form, they are likely to recognise that the increase is always the same multiple of the previous amount. If the unit growth factor should change in the future after a certain number of periods $m$ (where $m<n$ ), it may be possible for them to appreciate that the new formula will be $A_{n}=P\left(1+i_{1}\right)^{m}\left(1+i_{2}\right)^{n-m}$ where $i_{1}$ and $i_{2}$ are the different interest rates.

\section{Financial aspects of teachers' knowledge}

In order to unpack (Ball, Bass \& Hill, 2004) the mathematics of compound interest for learners, teachers will likely draw on percentage calculations and exponential growth. In addition, unpacking may involve some reference to the world of banking and the ways in which interest works in banks. In this section I discuss two elements of the contextual knowledge of finance that will enable teachers to make appropriate links between the mathematics of compound interest and banking practice. I begin with daily interest calculations, followed by a discussion of the efficiency and accuracy of the compound interest formula as a model of compound growth. I conclude this section with some suggestions of the broader financial and socio-economic knowledge that would enable teachers to give learners access to the everyday world of finance.

\begin{tabular}{|cccc|}
\hline Line & End of period & Expression for compounding & $\begin{array}{c}\text { Expression for } \\
\text { accumulated amount }\end{array}$ \\
\hline 1 & 1 & $A_{1}=P(1+i)$ & $A_{1}=P(1+i)$ \\
2 & 2 & $A_{2}=P(1+i)(1+i)$ & $A_{2}=P(1+i)^{2}$ \\
3 & 3 & $A_{3}=P(1+i)^{2}(1+i)$ & $A_{3}=P(1+i)^{3}$ \\
4 & $\vdots$ & & \\
5 & $n$ & $A_{n}=P(1+i)^{n-1}(1+i)$ & $A_{n}=P(1+i)^{n}$ \\
\hline
\end{tabular}

FIGURE 4: A multiplicative approach to deriving the compound interest formula.

\section{Interest in the world of banking}

Earlier I noted that the selected textbook examples did not reflect the complexity of the banking world where interest is calculated daily and (in most instances) compounded monthly. This means that interest calculations done each day use a daily interest rate, and interest is calculated on the balance in the account at midnight ${ }^{3}$. However, the interest is not added to the account until midnight on the last day of the month. Thus we need to distinguish between calculating interest and compounding interest. Each day banks use a percentage calculation to determine the amount of interest for the day. They do not make use of the simple or compound interest formula. Below I summarise the details of daily interest calculations with monthly compounding. Elsewhere I have used a 'bucket analogy' to illustrate this process of daily interest calculations and monthly compounding. (See Pournara, 2012, for a detailed discussion of this analogy.)

Consider a scenario where R500 is invested for a year at $10 \%$ p.a. with daily calculation of interest and monthly compounding, as shown in the spreadsheet extract in Table 1. Whilst all calculations were done with maximum accuracy, only some columns show six or more decimal places. The daily interest rate is based on a day count convention of 365 days, where the daily rate is calculated by dividing the nominal annual rate by 365 irrespective of the actual number of days in the year. Thus the cumulative interest for January is calculated as follows: $10 \% \div 365 \times 31 \times 500=\mathrm{R} 4.25$ (to two decimal places). Note that more interest accumulates in January than in February despite the opening balance for February being higher. This is because there are fewer days in February. Thus we see that in simple interest scenarios, the interest is not constant for each month.

If the spreadsheet is continued for a full year, it will give an accumulated amount of R552.356352 (to six decimal places) whilst the compound interest formula gives an answer of $\mathrm{R} 552.356354$ (to six decimal places). The difference is less than $0.0003 \%$.

\section{The compound interest formula as a model of compound growth}

The compound interest formula provides a very accurate and efficient model of daily interest calculations with monthly compounding. I discuss this briefly, but see Pournara (2012) for a more detailed illustration.

In order to compare the accuracy of the compound interest formula with actual calculations done in the bank, one needs to consider its implicit assumptions as well as the different day count conventions. The formula assumes that all months have the same number of days and that there are an equal number of days in each year. There is a range of different day count conventions in use across the world. Rand-based

3.In reality banks may not carry out this process exactly at midnight. It will take place at some point after close of business, and forms part of a broader daily reconciliation process that may take several hours to complete. I therefore refer to 'midnight' in a process that may take several hours to complete. I therefore refer to 'midnight' in a
metaphorical sense. The key issue is that interest is calculated (or compounded) at discrete points in time and not continuously. 
TABLE 1: Cumulative interest based on daily interest calculations and monthly compounding.

\begin{tabular}{|c|c|c|c|c|c|c|}
\hline Month & No of days & Opening balance & Daily interest rate & Daily interest & Cumulative interest for period & Closing balance \\
\hline January & 31 & 500.00 & 0.00027397260 & 0.136986 & 4.246575 & 504.25 \\
\hline February & 28 & 504.25 & 0.00027397260 & 0.138150 & 3.868193 & 508.11 \\
\hline March & 31 & 508.11 & 0.00027397260 & 0.139210 & 4.315495 & 512.43 \\
\hline April & 30 & 512.43 & 0.00027397260 & 0.140392 & 4.211756 & 516.64 \\
\hline
\end{tabular}

TABLE 2: Comparison of daily interest calculations versus predicted amounts.

\begin{tabular}{|c|c|c|c|c|c|}
\hline Day count convention & Actual number of days in year & Daily interest calculations & Predicted (Cl formula) & Difference (daily int. calc. - predicted) & $\%$ error \\
\hline 360 & 366 & 53.270107 & 52.35653372 & 0.913573279 & $1.7150 \%$ \\
\hline 365 & 366 & 52.506530 & 52.35653372 & 0.149996279 & $0.2857 \%$ \\
\hline actual & 365 & 52.356352 & 52.35653372 & -0.000181721 & $-0.0003 \%$ \\
\hline actual & 366 & 52.356432 & 52.35653372 & -0.000101721 & $-0.0002 \%$ \\
\hline
\end{tabular}

products use a 365-day convention whereas the typical standard for US dollar-based markets is 360 days. There are other markets that use an actual-day convention where the nominal annual rate is determined by the actual number of days in the year. In Table 2 I summarise the accuracy of the compound interest formula as a model of these three different scenarios. I compare the answer from daily interest calculations (as shown in Table 1) with the answer from the formula. I refer to the latter as the predicted answer. By choosing the most extreme case for each scenario, I indicate the maximum possible error. As can be seen, the maximum error is less than $1.72 \%$.

In this section I have shown that a gap exists between the notion of compound interest as presented in textbooks and the compounding of interest in the world of banking. If teachers are to bridge this gap for themselves and ultimately for their learners, they require a wide range of knowledge that is generally not found in school texts or universitylevel introductory financial mathematics texts. For example, they require contextual knowledge such as daily interest calculations and international day count conventions. They also require knowledge of basic modelling practices, including the notion of error in mathematical models, and appropriate metaphors and analogies to explain the daily banking process.

\section{Knowledge of socio-economic issues and financial literacy}

Ideally, mathematics teachers should give learners access to the everyday world of finance, in addition to mathematical basics of compound interest and annuities. To do this, they require knowledge of a range of financial concepts and conventions in addition to those mentioned above. This might include the notion of the time value of money, which is a fundamental construct underpinning all financial mathematics. Knowledge of interest rates such as the repo rate and prime rate is important since these ultimately impact the banks' rates. Changes in the repo and prime rates provide opportunity to gain an appreciation of the substantial impact over time of small changes in interest rates, particularly on loans. The distinction between nominal and real interest rates is important because the latter takes inflation into account; thus, some knowledge of inflation is also beneficial for teachers.
Teachers also require knowledge of general socio-economic issues and financial literacy. It is well-known that levels of financial literacy in South Africa are low (Eighty20, 2008), that levels of national and personal debt are extremely high, and that the general public does not appreciate the negative impact of compound interest on borrowed money (South African Reserve Bank, 2012). Therefore, mathematics teachers have a moral imperative to help learners to appreciate the power of compound interest on both investments and loans, thus increasing learners' levels of financial literacy. Whilst some might argue that this is not the responsibility of the mathematics teacher but rather of teachers of commercial subjects, I argue that an appreciation of the power of compounding comes from knowledge of exponential growth and it is the mathematics teacher who will open up learners' access to this knowledge.

Inevitably this raises concern about the breadth (Ma, 1999) of knowledge required of mathematics teachers. It could be argued that the knowledge of financial and economic issues identified above forms part of the knowledge base for general financial literacy of economically active citizens, and so a mathematics teacher who is financially literate will possess sufficient contextual knowledge. However, the detailed knowledge of daily compounding and day count conventions is not part of general financial literacy. This suggests that mathematics teachers' knowledge of financial and economic issues is specialised and extends beyond general levels of financial literacy.

\section{Pedagogical aspects of teachers' knowledge}

This section is concerned with aspects of a teacher's knowledge base for compound interest that are primarily pedagogical. However, as will be seen, mathematical aspects are always present in the background, and at times are brought into sharp focus. I begin with two instances of student error that emerged in the study, and conjecture that these errors may be a consequence of overgeneralisation of previous learning (Olivier, 1989). The first error relates to multiple compounding periods and the overgeneralisation of linear thinking. The second relates to depreciation and the overgeneralisation of reversible operations. Thereafter I make suggestions for the teaching of compound interest 
TABLE 3: Different interest amounts per month based on increasing balance.

\begin{tabular}{lcccccccccccccc}
\hline Month & $\mathbf{1}$ & $\mathbf{2}$ & $\mathbf{3}$ & $\mathbf{4}$ & $\mathbf{5}$ & $\mathbf{6}$ & $\mathbf{7}$ & $\mathbf{8}$ & $\mathbf{9}$ & $\mathbf{1 0}$ & $\mathbf{1 1}$ & $\mathbf{1 2}$ \\
\hline Portion of interest (\%) & 0.75 & 0.75 & 0.75 & 0.75 & 0.75 & 0.75 & 0.75 & 0.75 & 0.75 & 0.75 & 0.75 & 0.75 \\
Interest per month (R) & 2.25 & 2.27 & 2.28 & 2.30 & 2.32 & 2.34 & 2.35 & 2.37 & 2.39 & 2.41 & 2.43 & 2.44 \\
\hline
\end{tabular}

with particular attention to key tasks and exemplifying mathematical practices.

\section{Student error - multiple compounding periods and linear thinking}

Results from the study (Pournara, 2013) suggest that students have difficulty in distinguishing equal percentages of interest from equal amounts of interest, and may assume that equal interest rates per period imply equal amounts of interest per period. Thus, they do not distinguish adequately between relative quantities and absolute quantities. This error may not be exposed unless one explicitly focuses on the amount of interest per period, because the compound interest formula provides the final amount, which obscures how interest accumulates each period. The error may be evidence of overgeneralising of linear thinking (De Bock, Van Dooren, Verschaffel \& Janssens, 2002; Esteley, Villareal \& Alagia, 2010), but it may also be a consequence of distortions from rounding and of the way we talk about accumulating interest.

When dealing with multiple compoundings, the nominal annual rate is sub-divided into equal portions, depending on the number of compounding periods in the year, producing an effective interest rate per period. For example, a payment of R300 growing at a nominal annual rate of $9 \%$ p.a. compounded monthly gains $0.75 \%$ interest each month, since 9 is divided into 12 equal portions of 0.75 . However, the amount of interest associated with this monthly rate is different each month because of compounding on the latest balance. In Table 3 it can be seen that interest for the first month is R2.25 but interest for the second month is R2.27 (rounded to two decimal places).

Adding the twelve interest amounts gives total interest of R28.14, which is confirmed by the compound interest formula $F V=300\left(1+\frac{9 \%}{12}\right)^{12}=R 328.142$. But, although the formula is efficient, it hides the calculation of interest each month and thus the fact that the amount of monthly interest is not constant.

The ratios of the interest from month to month are clearly constant (at 1.0075) but the arithmetic difference is not constant. However, this may be obscured or distorted by the chosen numbers and by rounding. For example, the differences in interest between months 9 and 10, months 10 and 11, and months 11 and 12 are $2 c, 2 c$ and $1 c$ respectively. This appears to contradict the idea that amount of interest increases each month, and that the amount by which it increases also increases. This apparent contradiction is a consequence of rounding. Table 4 gives the amount of interest rounded to five decimal places and shows that the interest amounts are indeed growing each month, and that the rate of increase is
TABLE 4: Amount of interest rounded to five decimal places.

\begin{tabular}{lcccc}
\hline Month & $\mathbf{9}$ & $\mathbf{1 0}$ & $\mathbf{1 1}$ & $\mathbf{1 2}$ \\
\hline Interest (R, to 5 d.p.) & 2.38860 & 2.40651 & 2.42456 & 2.44274 \\
Difference in interest (R) & 0.01778 & 0.01791 & 0.01805 & 0.01818 \\
\hline
\end{tabular}

also increasing. However, when these figures are rounded to two decimal places, they produce the incorrect picture shown above.

Another contributing factor is the choice of numbers. The choice of R300 and 9\% in the above example yields very small amounts of monthly interest and even smaller second order differences. In order to illustrate the non-constant arithmetic difference more clearly, it would be wiser to choose values such as R5000 and 20\%. However, it should then be acknowledged that an interest rate of $20 \%$ p.a. is not a realistic figure in the current financial context. A third contributing factor is the way we talk of interest. We speak of adding interest to the balance at the end of each month, and so it is not surprising that our tendency is to reason additively when comparing the interest amounts in the table. Whilst we are indeed adding interest, the amount we add is generated by a multiplicative process.

\section{Student error - percentage change and reversible operations}

As discussed above, percentage is a key concept underpinning financial mathematics, but it is a difficult concept to learn. One of the biggest sources of difficulty stems from the asymmetric nature of percentage increase and decrease; this difficulty extends into adulthood (Parker \& Leinhardt, 1995). For example, increasing some amount $A$ by $10 \%$ produces a new amount $A^{\prime}$, but decreasing $A^{\prime}$ by $10 \%$ does not fully undo the increase and so the answer is not $A$. It seems reasonable to conjecture that the source of this error is an over-generalisation of the symmetric nature of the familiar operations of addition-subtraction and multiplication-division. In financial mathematics this appears to lead to errors in distinguishing depreciation from discounting. In order to appreciate students' difficulties, it is useful to compare and contrast appreciation, depreciation, compounding and discounting. In Figure 5 I define each term and provide a formula for each process.

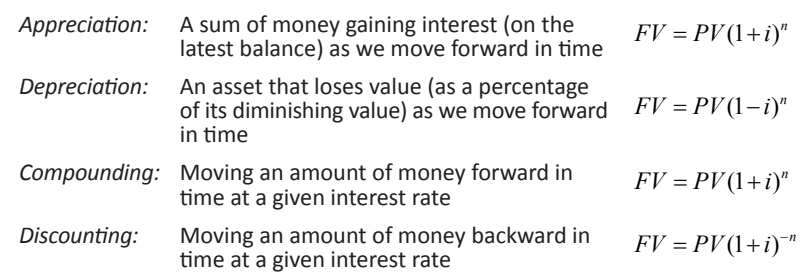

$F V$, Future value; $P V$, Present value.

FIGURE 5: Definitions of terms. 
The formulae show that the notion of unit growth factor $(1 \pm i)$ applies to all four processes, that appreciation and compounding make use of the same formula, and that compounding and discounting are reverse operations (and hence symmetrical), but appreciation and depreciation are not. In my experience, students may view depreciation as the reverse of appreciation or compounding.

Consider Question 2 from the textbook examples discussed above. Using the compound interest formula, we can determine that $P V=\frac{4500}{\left(1+\frac{425 \%}{4}\right)^{20}}=R 3642.60$. However, students may approach such problems by depreciating the future value for 20 periods as follows: $P V=4500\left(1-\frac{4.25 \%}{4}\right)^{20}=R 3634.39$. This error suggests that students are treating compounding and depreciation (with reducing balance) as reverse operations. This is not surprising on one level because the compounding process 'adds on' a percentage of the latest balance at the end of each compounding period, whilst the depreciation process removes a percentage of the balance. The error lies in the referent to which the percentage applies, but this may be less obvious when using the formulae than it is when doing a single percentage change calculation.

Whilst the discussion above may not be appropriately calibrated for school level, it highlights some of the knowledge required by teachers. Firstly, mathematical knowledge that the 'multiplicative differences' (i.e. ratios) are constant but the 'additive differences' are not. Secondly, knowledge of how learners may reason; for example, (1) learners may notice the different gaps between amounts and question the apparent contradiction that the rate of increase of the interest is not always increasing, (2) that a comparison based on additive reasoning is intuitive and sensible, (3) that the 'additive problem' does not lie in rounding of monetary amounts, but (4) that a comparison based on ratios is constant (and is based on the unit growth factor $(1+i)$. Furthermore, teachers require knowledge of how to explain that the ratios are equal, and why the differences are not. This is indeed a challenging task.

\section{Implications for teaching compound interest}

As noted earlier, the curriculum constraints place substantial limitations on what might be achievable in terms of teaching and learning compound interest. Nevertheless, in this section I make some suggestions for opportunities to capitalise (pun intended!) on compound growth to expose learners to more general mathematical practices. I also identify four key tasks that lever up key mathematical ideas that extend beyond the realm of compound interest.

Although compound interest tasks at school level tend to focus on numeric work, there are various opportunities to attend to other mathematical practices, such as:

- Working to different levels of accuracy and the impact of rounding on financial calculations.

- Working inductively, as exemplified in the derivation of the simple and compound interest formulae.
- Working with inverse and reversible operations; see above for a discussion of appreciation, depreciation, compounding and discounting.

- Working with proof on two cases of counter-intuitive phenomena related to compound growth: students can use school-level algebra to prove that the time for an amount to double is independent of the amount of money, and graphical illustrations can be used to show powerfully that compound growth is slower than linear growth within the first compounding period.

Related to these practices I suggest three tasks that foreground the key ideas of compound interest whilst simultaneously exemplifying key mathematical ideas:

- Strategic choices for interest rates that do and do not lead to a recurring decimal value in relation to the compounding period. Such choices are determined by the goals of the task: it may not be desirable to include the complexity of a recurring decimal when focusing on the impact of the number of compounding periods, but it is essential to work with a recurring decimal value to emphasise the impact of rounding errors in financial calculations; for example, $6.5 \%$ p.a. compounded monthly gives a nominal monthly rate of $0.541666 \ldots \%$.

- When compounding, the growth of any amount tends to a limit. Based on the limited range of examples of multiple compounding periods that learners are exposed to, they may assume that the amount of interest increases without bound as the number of compounding periods increases. However, it can be shown both numerically and analytically that the accumulated interest tends to a limit as the number of compounding periods tends to infinity. (See Samson \& Pournara, 2013, for a detailed discussion.)

- Simple interest grows faster than compound interest in the first compounding period. Whilst learners soon appreciate that compound interest has a higher yield than simple interest at the same interest rate over the same time period, it is not intuitive that this relationship is reversed during the first compounding period. For example, if R300 is invested at $12 \%$ p.a. with simple interest (1\%) added at the end of each month, by the end of month 6 it will have grown to R318. By contrast if the same amount is compounded annually at the same rate, it will grow to only $300(1.12)^{0.5}=R 317.49$ by the end of six months.

\section{Conclusion}

In this article I have illustrated the specificity of teacher's mathematical knowledge for teaching compound interest, and have argued that it has mathematical and pedagogical components, as well as requiring contextual knowledge of finance. I have proposed a theoretical elaboration of the notion of compound interest and discussed two errors made by students in the broader study. In discussing key practices of working with interest in the banking sector, I have shown how these practices are removed from the typical examples of compound interest questions found in textbooks. Much work remains to be done to research the teaching and learning of compound interest, and the extent to which 
teachers' knowledge enables learners not only to answer textbook and assessment questions, but also to develop a useable knowledge of finance beyond the classroom.

\section{Acknowledgements}

This work was supported financially by the Thuthuka programme of the National Research Foundation (NRF, grant no. TTK2007050800004). Any opinions, findings and conclusions or recommendations expressed are those of the author and the NRF does not accept any liability.

\section{Competing interests}

I declare that I have no financial or personal relationships that may have inappropriately influenced me in writing this article.

\section{References}

Adler, J. (2005). Mathematics for teaching: What is it and why is it important that we talk about it? Pythagoras, 62, 2-11. http://dx.doi.org/10.4102/pythagoras.v0i62.109

Adler, J., \& Ball, D. (2009). Knowing and using mathematics in teaching. For the Learning of Mathematics, 29(3), 2-3.

Adler, J., \& Davis, Z. (2006). Opening another black box: Researching mathematics for teaching in mathematics teacher education. Journal for Research in Mathematics

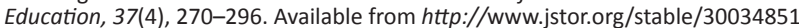

Bakker, A., Kent, P., Noss, R., Hoyles, C., \& Bhinder, C. (2006). 'It's not just magic!' Learning opportunities with spreadsheets in the financial sector. In D. Hewitt (Ed.) Proceedings of the British Society for Research into Learning Mathematics, Vol. 26(1) (pp. 17-22). London: BSRLM. Available from http://www.bsrlm.org.uk/IPs/ ip26-1/BSRLM-IP-26-1-4.pdf

Ball, D., Bass, H., \& Hill, H. (2004, January). Knowing and using mathematical knowledge in teaching: Learning what matters. Paper presented at the 12th Annual Conference of the Southern African Association for Research in Mathematics, Science and Technology Education, Cape Town.

Ball, D., Thames, M., \& Phelps, G. (2008). Content knowledge for teaching: What makes it special? Journal of Teacher Education, 59(5), 389-407. http://dx.doi.org/10.1177/ 0022487108324554

Beal, D., \& Delpachitra, S. (2003). Financial literacy among Australian university students. Economic Papers, 22(1), 65-78. http://dx.doi.org/10.1111/j.1759-3441.2003. tb00337.x

Bennie, K., Blake, P., \& Fitton, S. (2006). Focus on Mathematics Grade 11 Learner's Book. Cape Town: Maskew Miller Longman.

Brown, M., Küchemann, D., \& Hodgen, J. (2010, April). The struggle to achieve multiplicative reasoning 11-14. Paper presented at the British Congress for Mathematics Education (BCME-7), University of Manchester, Manchester.

Chen, H., \& Volpe, R. (1998). An analysis of personal financial literacy among college students. Financial Services Review, 7(2), 107-128. http://dx.doi.org/10.1016/ S1057-0810(99)80006-7

Cross, J., Cross, S., Joshua, L., Mahlaba, F., Mnyandu, P., Mogambery, M., et al. (2005) Shuters Mathematics Grade 10 Learner's Book. Pietermaritzburg: Shuter \& Shooter.

De Bock, D., Van Dooren, W., Verschaffel, L., \& Janssens, D. (2002). Improper use of linear reasoning: An in-depth study of the nature and irresistibility of secondary school students' errors. Educational Studies in Mathematics, 50, 311-334. http:// dx.doi.org/10.1023/A:1021205413749

Dempsey, S. (2003). On the benefits of a mathematical solutions approach to time value of money instruction: Arguments and evidence. Journal of Accounting Education, 21, 239-260. http://dx.doi.org/10.1016/S0748-5751(03)00023-X

Department of Basic Education. (2011). Curriculum and assessment policy statement Grades 10-12 Mathematics. Pretoria: DBE

Department of Education. (2002). Revised national curriculum statement Grades R-9 (Schools) Mathematics. Pretoria: DOE
Eighty20. (2008). What do we know about financial literacy in South Africa? Cape Town: Eighty20.

Esteley, C., Villareal, M., \& Alagia, H. (2010). The overgeneralization of linear models among university students' mathematical productions: A long-term study. Mathematical
Thinking and Learning, 12, 86-108. http://dx.doi.org/10.1080/10986060903465988

Even, R. (1990). Subject matter knowledge for teaching and the case of functions. Educational Studies in Mathematics, 21(6), 521-544. http://dx.doi.org/10.1007/ BF00315943

Even, R. (1993). Subject-matter knowledge and pedagogical content knowledge: Prospective secondary teachers and the function concept. Journal for Research in Mathematics Education, 24(2), 94-116. http://dx.doi.org/10.2307/749215

Geiger, V., \& Goos, M. (1996). Number plugging or problem solving? Using technology to support collaborative learning. In Proceedings of the Nineteenth Annual Conference of the Mathematics Education Research Group of Australasia (pp. 229-236) Melbourne: MERGA. Available from http://www.merga.net.au/documents/RP_ Geiger_Goos_1996.pdf

Hoyles, C., Noss, R., Kent, P., \& Bakker, A. (2010). Improving mathematics at work: The need for techno-mathematical literacies. Oxon, UK: Routledge.

Huillet, D. (2009). Mathematics-for-teaching: An anthropological approach and its elaboration in teacher training. For the Learning of Mathematics, 29(3), 4-10.

Jalbert, T., Jalbert, M., \& Chan, C. (2004). Advances in teaching the time value of money. Journal of College Teaching and Learning, 1(8), 7-12.

Laridon, P., Barnes, H., Jawurek, A., Kitto, A., Pike, M., Myburgh, M., et al. (2006). Classroom Mathematics Grade 11 Learners' Book. Sandton: Heinemann. PMid:16451137

Ma, L. (1999). Knowing and teaching elementary mathematics: Teachers' understanding of fundamental mathematics in China and the United States. Mahwah, NJ: Lawrence Erlbaum.

Noss, R., \& Hoyles, C. (1996a). The visibility of meanings: Modelling the mathematics of banking. International Journal of Computers for Mathematical Learning, 1, 3-31. $\mathrm{http}: / / \mathrm{dx}$.doi.org/10.1007/BF00191470

Noss, R., \& Hoyles, C. (1996b). Windows on mathematical meanings: Learning cultures and computers. Dordrecht: Kluwer. http://dx.doi.org/10.1007/978-94-009-1696-8

Olivier, A. (1989). Handling pupils' misconceptions. Pythagoras, 21, 10-19.

Organisation for Economic Cooperation and Development. (2005). Improving financia literacy: Analysis of issues and policies. Paris: OECD.

Parker, M. \& Leinhardt, G. (1995). Percent: A privileged proportion. Review of Educational Research, 65(4), 421-481. http://dx.doi.org/10.3102/00346543065004421

Pournara, C. (2012). Does the compound interest formula give us the 'real' answer? Learning and Teaching Mathematics, 12, 24-26.

Pournara, C. (2013). Mathematics-for-teaching in pre-service secondary mathematics teacher education: The case of financial mathematics. Unpublished doctoral dissertation. University of Witwatersrand, Johannesburg, South Africa.

Samson, D., \& Pournara, C. (2013). Why increasing the number of compounding periods won't make you as rich as you might think. Learning and Teaching Mathematics, $14,26-30$.

Sfard, A. (1991). On the dual nature of mathematical conceptions: Reflections on processes and objects as different sides of the same coin. Educational Studies in Mathematics, 22, 1-36. http://dx.doi.org/10.1007/BF00302715

Sfard, A. (1992). Operational origins of mathematical objects and the quandary of reification: The case of function. In G. Harel, \& E. Dubinsky (Eds.), The concept of function: Aspects of epistemology and pedagogy (pp. 59-84). Washington, DC Mathematical Association of America.

Sfard, A., \& Linchevski, L. (1994). The gains and pitfalls of reification - The case of Algebra. Educational Studies in Mathematics, 26, 191-228. http://dx.doi.org/ 10.1007/BF01273663

Shulman, L. (1986). Those who understand: Knowledge growth in teaching. Educationa Researcher, 15(2), 4-14. http://dx.doi.org/10.3102/0013189X015002004

Shulman, L. (1987). Knowledge and teaching: Foundations of the new reform. Harvard Educational Review, 57(1), 1-22.

South African Reserve Bank. (2012). Quarterly Bulletin No. 263, March 2012. Pretoria: South African Reserve Bank.

Thompson, A., \& Thompson, P. (1996). Talking about rates conceptually, Part II: Mathematical knowledge for teaching. Journal for Research in Mathematics Education, 27(1), 2-24. http://dx.doi.org/10.2307/749194

Thompson, P. (1994). Images of rate and operational understanding of the Fundamental Theorem of Calculus. Educational Studies in Mathematics, 26(2-3), 229-274. http:// dx.doi.org/10.1007/BF01273664

Zandieh, M. (2000). A theoretical framework for analyzing student understanding of the concept of derivative. CBMS Issues in Mathematics Education, 8, 103-127. 